\title{
The Education Method Research Based on the Cooperation between University and Industry
}

\author{
Yu Xia ${ }^{1, a}$, Xiao-lian Zhao ${ }^{2, b}$, and Zhong-qing Zhang ${ }^{3, c}$ \\ ${ }^{1}$ Civil Engineering and Architecture college of Guangxi University of Science and Technology, \\ Liuzhou, China \\ ${ }^{2}$ College of Resources and Environment, Guangxi University, Nanning China \\ ${ }^{3}$ College of Civil and Architecture Engineering, Guangxi University, Nanning, China \\ asumm-rain@163.com, bxiaolianbsh@126.com, 'changzq@gxu.edu.cn
}

Keywords: university-industry, cooperation base, education reform

\begin{abstract}
At present, the number of graduate is growing larger and lager in China, while the education resource for graduate is comparatively limited. Under the guidance of university-industry policy of China, many universities try to cooperate with industry to educate graduate. This paper does analysis of the existing problems about the cooperation at currency, and then it gives some suggestion for improving the cooperation.
\end{abstract}

\section{Introduction}

The join of university and industry, means that they share special teaching resource of their own for graduate education. This helps to unify the resource of enterprise, high school and institution. They hope the powerful combination to promote education and will lead to a number of high-level researchers, who will find, propose and solve problem independently in research. It will improve the technique and strengthen the ability of competition of the enterprise. The cooperation has an important practical value [1, 2]. Recently, the Chinese government has invested more and more money in science and technology innovation year by year to encourage the cooperation, including projects, talent, platform and other aspects [3]. The industry and university working together for research and production has been discussed in many articles [4-6]. The cooperation is a win-win choice. For industry, on the one hand, it will easily produce the most needed high-level talents, on the other hand, technical problems will be dealt with during study process. For high school, on the one hand, it expands the research sources and improves students' ability to solve practical problem, on the other hand, students will be easy to join the same enterprise after graduation. The cooperation also shows some new questions, which are ever seen before. The paper will discuss the existing questions and give some suggestions on how to promote a comprehensive cooperation.

\section{The existing problems of university-enterprise cooperation}

The student in cooperation usually finds they are difficult to have a meet with their supervisor. The tutor is so busy and always on business or having a meeting. So the student sometimes are absent from university without any administrative process. When they finish the study of basic course, the paper is usually written in industry. There are some problems in the management. The regulation rules of enterprise do not applied to the students from university, because they are not the real staff. They are also out of the school supervision. It is hard to carry out an effective management.

Management of graduate. The appropriate staff from enterprise will be selected to be the supervisor of graduate. There are strict rules for the selection. For example, the candidate must have a few research projects, representative publications and research awards or patents received in recent years. The applicants' current title is also taken into account. Usually, the staff with senior technique can not fully meet the above required conditions. 
Supervisor selection from enterprise. There are strict requirements for full-time master's thesis in university. For example, it takes one year to finish the thesis at least, the paper must have a certain depth and innovation. For enterprise, they emphasize the practical technique. So graduate thesis is more like a technical summary of the project, the paper lacks depth and innovation.

Quality control of thesis. In the beginning stage of the school-enterprise cooperation, postgraduate help some companies solve technical problems of a project. With the deepening and expanding of cooperation between universities and enterprises, students have more chance to know the company's core technology. Intellectual property right will be a problem that both parts have to face. How to keep the company's core technology privacy, and how to share the achievements of cooperation between the two parts, these problems need to be solved at the beginning of cooperation

Insurance of graduation. There are some concerns for some universities. When students begin research in the company, they are under supervision of the company. The university should be responsible for any of their accident or injury, how to ascertain the duty and obligation is also an issue to be solved.

Management of supervisor from enterprise. The tutors selected from enterprise have responsibilities and obligations of graduate guidance. How to regulate the guidance for thesis, how to make the paper meet the requirement of university, solving the technical problems of the enterprise at the same time and avoiding students becoming a called "cheap wage earners", the appropriate regulations are also needed.

Education programs. Knowledge needed in enterprise may be a little different from that of university. The relevant courses may not list in education program. The education program should be more flexible.

Method to the problems. From the above discussion of university-enterprise cooperation, it can be found that it should establish a set of management regulations to the behavior of company and university.

Graduate Management Regulations. The management of graduate should be divided into two stages. During the first stag, the student study in university and should obey the relevant regulations of university. There will be a deputy supervisor for students who have a supervisor from enterprise. The deputy supervisors usually have the same research interests with the enterprise. They are mainly responsible for the daily study and living in university. When supervisor of enterprise is on business, the deputy will take his place. The deputy also should regularly make report to the chief supervisor. Once students begin to write their papers, they may stay in enterprise most of the time. The chief advisor is directly in charge of students. The appropriate regulations, which are suitable for student, are also should be let every student known. They must obey the regulations. It's much better the requirements of the enterprise are in accordance with those of university. Students should comply with the basic enterprise regulations. If they violate the provisions, they will be given some punishment. According to how worse the matter is, they will be imposed warnings, penalties, cancellation degree and other penalties. The most worse may be expelled from university. The sub-commission usually discusses the penalty and forms an opinion, and then the opinion is sent to committee of university for final approval.

Business mentors Regulations. For supervisor selection, if the candidates can not meet the requirements of university, the criteria can be more flexible, but it should be made sure that the selected supervisors have the ability and resource to guiding graduate. For example, the candidate has national research projects, won the scientific awards of provincial or ministerial level, won important national invention patents recently. The supervisor from enterprise will receive the same reward as those in university. Each of them will accept an annual assessment. Only the passing persons will be employed. Once appointed, the persons must accept the training for supervisor to know about the relevant regulations, responsibilities and obligations.

Postgraduate Medical and insurance regulations. The graduate in enterprise should buy insurance. The cost of purchasing insurance will be shared by the university and enterprise, the insurance generally covers personal security and health. 
Intellectual Property Ordinance . Before the graduate has chance to know the core technology, they will be asked to sign agreement with the enterprise which will make sure the student will not reveal any information about the technology. If they violate the rules of the agreement, they will bear the responsibility. Intellectual property will be shared by both enterprise and company, such as papers, patents, inventions, awards. All the matters above should reach an agreement before cooperation.

Graduate education program. Because the particularity of research project in enterprise, some courses may not in the education program. The supervisor from enterprise should take part in the education program formulation. Then the courses needed will be added into the new program. In order to select the desired students with the right knowledge and technology which are needed in enterprise project, the supervisors from enterprise may take part in the interview to select the proper graduate.

\section{Driving of school-enterprise cooperation}

After the school-enterprise cooperation carried out, there is still a lot of work to do to promote a long, comprehensive and deep cooperation.

First, establish a training base of university and enterprise, it will help to build a platform for educating large number of talents with advanced theory and skills. Refining the management regulations of the base is also a must. University and enterprise will offer some facilities and money to build the base according to the need of research, they both will share the research achievements.

Apply for key laboratory of special local characteristics, combining the resource of the two parts to create a platform for the both to cooperate in-depth. Meanwhile, for some of the key technical problems, it could set an open fund to the country, providing laboratory, equipment and funding.

For some key research problem, apply for a key national or regional research projects, and then unify the researchers of the two sides to overcome the problems.

The thesis of graduates should focus on the most encouraged field of nation or local area or the most imperative field of factory. The graduates are able to deal with the matters of enterprise immediately after graduation. It's much easier for them to get a job, the enterprise is also satisfied with the new staff that is familiar with the works. The win-win situation will promote the cooperation of the two sides.

Establish appropriate reward fund. For businesses, those ones who can solve the key technical problems, either graduate or university teachers, will be given certain economic incentives. For colleges and universities, those who have important patent or research papers of high scientific level will be given appropriate money as a reward.

Expand the scope of cooperation, teachers are also encouraged to do research in the enterprise. Let young teachers with well educated and profound theory background conduct research to solve technical problems and learn the advanced technology of enterprise, they will know the problems which enterprises are facing. The more the two sides cooperate, the more achievements will be received. Meanwhile, personnel departments of university should perform more flexible policies, paves the way for university teachers conducting research in enterprise.

According to the development needs of the cooperate base, a few excellent graduate or supervisors should be sent to other university or enterprises either home or abroad for a further education. They will learn educating program, and management regulations and operating mechanism. When they come back, they will improve the servicing ability of the cooperate base, expand the scale of the base and make it a good research platform for practices and implementation.

\section{Acknowledgements}

This paper is supported by Graduate Education Innovation Program of Guangxi (JGY2013054), Undergraduates' Innovation and Practise Training Program of China Education Ministry (201310594009) and Guangxi Undergraduates' Innovation and Practise Training Program . 


\section{References}

[1] Jan-ming Zuo, Lijuan Zhang. A comparative study of university-industry collaboration. Jiangsu Higher Education. Vol.05 (2002). p.115-117

[2] Xing-yi Wu, Yong-rong Yang etc, The education method of university-industry collaboration and engineering graduate. Chemical Higher Education. Vol. 2(2002). P.78-80

[3] Qiu-feng Wu. Construction of base for graduate. Heilongjiang Higher Education Research. Vol. 05(2008). p.125-126

[4] Min Jing, Yu-chao Niu. The industy-universty for the cultivation of graduate based on the co-built laboratory. The forum of teaching and education. Vol. 04 (2012). P.129-130

[5] Shi-yi Ou. The cultivation of graduate based on cooperation of university and industry. Higher science education. Vol.04 (2005). P.25-26

[6] Jing Wen, Wei-Jiu Huang, Yun-yun Luo. The cultivation mode research based on the cooperation of university and industry. China Electric Power Education. Vol.02 (2009) p.19-20 